\title{
Real Time Implementation of Fuzzy Adaptive PI-sliding Mode Controller for Induction Machine Control
}

\author{
Mohamed Habbab ${ }^{1}$, Abdeldjebar Hazzab ${ }^{2}$, Pierre Sicard ${ }^{3}$ \\ ${ }^{1,2}$ Laboratoire de Recherche Commande, Analyse et Optimisation des Systèmes Electro- énergétiques, université TAHRI \\ Mohamed de Bechar, Algeria \\ ${ }^{3}$ Groupe de Recherche en Electronique Industrielle (GREI) Université du Québec à Trois-Rivières \\ C.P.500, Canada
}

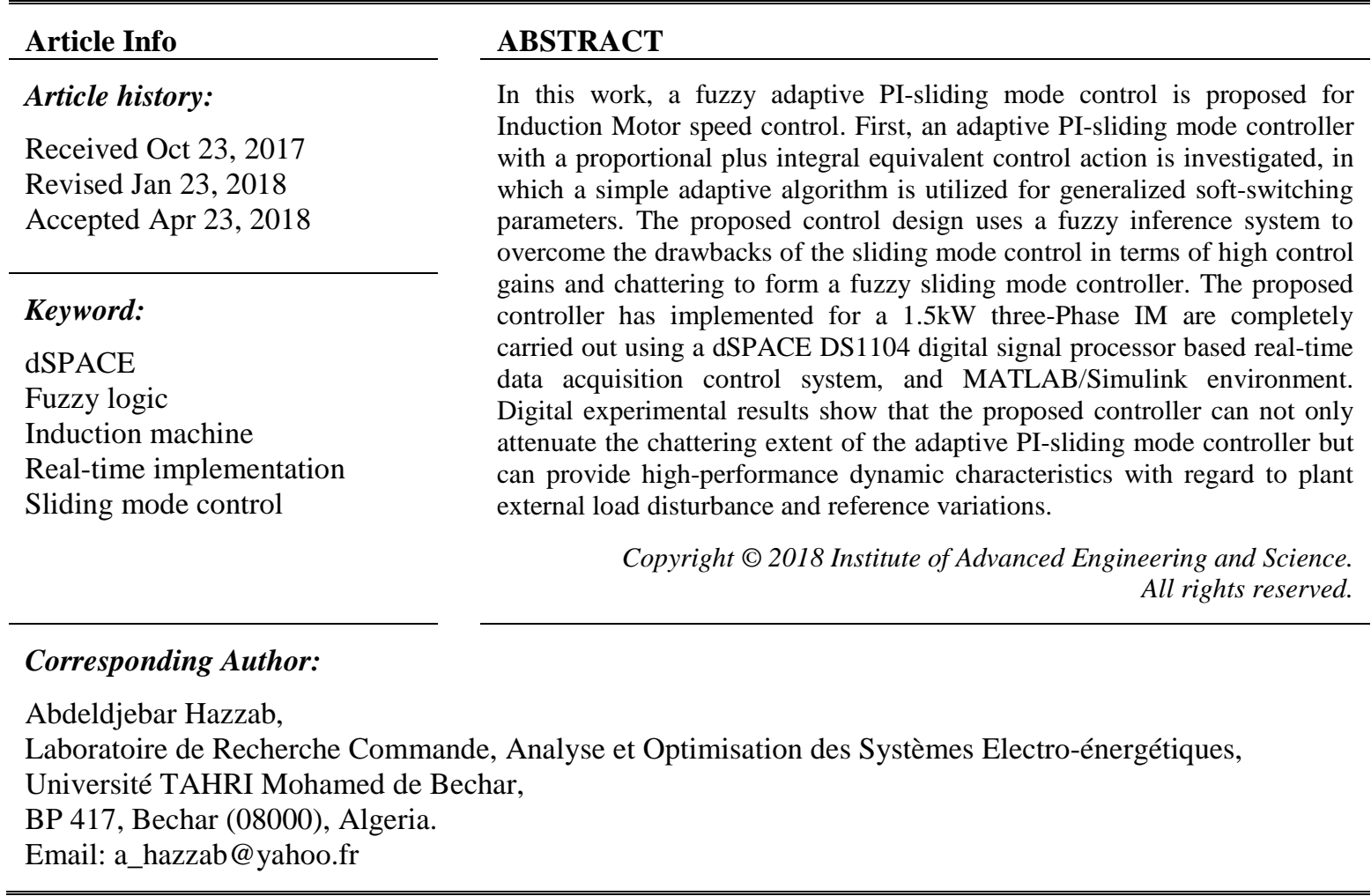

\section{INTRODUCTION}

Sliding mode control (SMC) has for long been known for its capabilities in accounting for modeling imprecision and bounded disturbances. It achieves robust control by adding a discontinuous control signal across the sliding surface, satisfying the sliding condition. However, in SMC, the high frequency chattering phenomenon that results from the discontinuous control action is a severe problem when the state of the system is close to the sliding surface [1],[2].

To simplify the equivalent control of the classical SMC and ease the design task for practicing engineers [3],[4], an adaptive PI-sliding mode controller (APISMC) is used which the equivalent control action based on the proportional plus integral control law with generalized hard-switching parameters [5]-[7]. A potential advantage of this strategy is its ability of using the undistorted nonlinear model of the physical system in a simulation based design process [6].

In various nonlinear system control issues, fuzzy controller is recently a popular method to combine with sliding mode control method that can improve some disadvantages in this issue. Comparing with the classical control theory, the fuzzy control theory does not pay much attention to the stability of system, and the stability of the controlled system cannot be so guaranteed. In fact, the stability is observed based on following two assumptions: First, the input/output data and system parameters must be crisply known. Second, the system has to be known precisely. The fuzzy controller is weaker in stability because it lacks a 
strict mathematics model to demonstrate, although many researches show that it can be stabilized anyway [8],[9]. Nevertheless, the concept of a sliding mode controller (SMC) can be employed to be a basis to ensure the stability of the controller [10]. The feature of a smooth control action of FLC can be used to overcome the disadvantages of the SMC systems (chattering phenomenon) [11],[12]. This is achieved by merging of the FLC with the variable structure of the APISMC to form Adaptive Fuzzy PI-Sliding Mode Controller (FAPISMC). In this hybrid control system, the strength of the sliding mode control lies in its ability to account for modeling imprecision and external disturbances while the FLC provides better damping and reduced chattering.

To demonstrate the effectiveness of the proposed control scheme, we apply the proposed scheme to the speed control of a three-phase induction motor using a dSPACE DS1104 digital signal processor (DSP) based real-time data acquisition control (DAC) system, and MATLAB/Simulink environment. The proposed controller has been achieved, fulfilling the robustness criteria specified in the sliding mode control and yielding a high performance in implementation to induction motor speed control. This paper is organized as follows: In section II, we present the indirect field-oriented control of the IM, the synthesis of the Adaptive PI-Sliding Mode Controller is outlined in section III. In section IV we present the synthesis of the Fuzzy Adaptive PI-Sliding Mode Controller. Experimental results and performance of the controllers are compared in section V. Finally, some remarking conclusions are summarized in Section VI.

\section{INDIRECT FIELD-ORIENTED CONTROL OF THE THE INDUCTION MOTOR}

The machine considered in this paper, is a three-phase squirrel-cage asynchronous machine. The dynamic model of the $\Delta$-connected induction motor can be expressed in the d-q synchronously rotating frame as [13],[14]:

$$
\left\{\begin{aligned}
\frac{d i_{s d}}{d t}= & -\left(\frac{R_{s}}{\sigma L_{s}}+\frac{1-\sigma}{\sigma \tau_{r}}\right) i_{s d}+\omega_{e} \cdot i_{s q}+\frac{L_{m}}{\sigma L_{s} L_{r} \tau_{r}} \phi_{r d} \\
& +\frac{L_{m} \omega_{r}}{\sigma L_{s} L_{r} \tau_{r}} \cdot \phi_{r q}+\frac{1}{\sigma L_{s}} V_{s d} \\
\frac{d i_{s q}}{d t}= & -\omega_{e} \cdot i_{s d}-\left(\frac{R_{s}}{\sigma L_{s}}+\frac{1-\sigma}{\sigma \tau_{r}}\right) i_{s q}-\frac{L_{m} \omega_{r}}{\sigma L_{s} L_{r} \tau_{r}} \cdot \phi_{r d} \\
& +\frac{L_{m}}{\sigma L_{s} L_{r} \tau_{r}} \phi_{r q}+\frac{1}{\sigma L_{s}} V_{s q} \\
\frac{d \phi_{r d}}{d t}= & \frac{L_{m}}{\tau_{r}} i_{s d}-\frac{1}{\tau_{r}} \phi_{r d}+\left(\omega_{e}-\omega_{r}\right) \phi_{r q} \\
\frac{d \phi_{r q}}{d t}= & \frac{L_{m}}{\tau_{r}} i_{s q}-\frac{1}{\tau_{r}} \phi_{r q}+\left(\omega_{e}-\omega_{r}\right) \phi_{r d} \\
\frac{d \omega_{r}}{d t}= & \frac{3}{2} \frac{P^{2} L_{m}}{J L_{r}}\left(i_{s q} \cdot \phi_{r d}-i_{s d} \cdot \phi_{r q}\right)-\frac{f_{c}}{J} \cdot \omega_{r}-\frac{P}{J} T_{1}
\end{aligned}\right.
$$

where $\sigma$ is the coefficient of dispersion and is given by

$$
\sigma=1-\frac{L_{m}{ }^{2}}{L_{r} \cdot L_{s}}
$$

where: ${ }^{L_{s}},{ }^{L_{r}}$ and ${ }^{L_{m}}$ : stator, rotor, and mutual inductances

$R_{s}$ and $R_{r}$ : stator and rotor resistances

$\omega_{e}$ and $\omega_{r}$ : electrical and rotor angular frequency

$\omega_{s l}$ : slip frequency $\left(\omega_{e}-\omega_{r}\right)$

$\tau_{r}$ : rotor time constant $\left(L_{r} / R_{r}\right)$

$P$ : number of pole pairs 
The main objective of the vector control of induction motors is, to control independently the flux and he torque as DC machines, this is done by using a d-q rotating reference frame synchronously with the rotor flux space vector [6],[13]. In ideally field-oriented control, the rotor flux linkage axis is forced to align with the d-axes, and it follows that:

$$
\begin{aligned}
& \phi_{r q}=\frac{d \phi_{r q}}{d t}=0 \\
& \phi_{r d}=\phi_{r}
\end{aligned}
$$
described as:

Considering (3) and (4), the torque equation becomes analogous to that of the dc machine and can be

$$
T_{e}=\frac{P \cdot L_{m}}{L_{r}} \phi_{r d} \cdot i_{s q}
$$

The decoupling control method with compensation is to obtain the inverter output voltages such that:

$$
\begin{aligned}
& V_{s d}^{*}=\left(K_{p}+K_{i} \frac{1}{s}\right)\left(i_{s d}^{*}-i_{s d}\right)-\omega_{e} \sigma L_{s} i_{s q}^{*} \\
& V_{s q}^{*}=\left(K_{p}+K_{i} \frac{1}{s}\right)\left(i_{s q}^{*}-i_{s q}\right)+\omega_{e} \sigma L_{s} i_{s d}^{*}+\omega_{e} \frac{L_{m}}{L_{r}} \phi_{r d}
\end{aligned}
$$

By using, the placement poles method the proportional and integral gains of the PI speed controller ( $K_{p}$ and $\left.K_{i}\right)$ are determined by [6]:

$$
\begin{aligned}
& K_{p}=\frac{2 \cdot \rho \cdot J-f_{c}}{P} \\
& K_{i}=\frac{2 \cdot J \cdot \rho^{2}}{P}
\end{aligned}
$$

Where the desired poles are: $s_{1,2}=\rho(-1 \pm j)$, the value of $\rho$ is given in appendix. The configuration of the overall control system is shown in Figure 1. It mainly consists of an induction motor, a ramp comparison current-controlled pulse width modulated (PWM) inverter, a slip angular speed estimator, an inverse park, an outer speed feedback control loop.

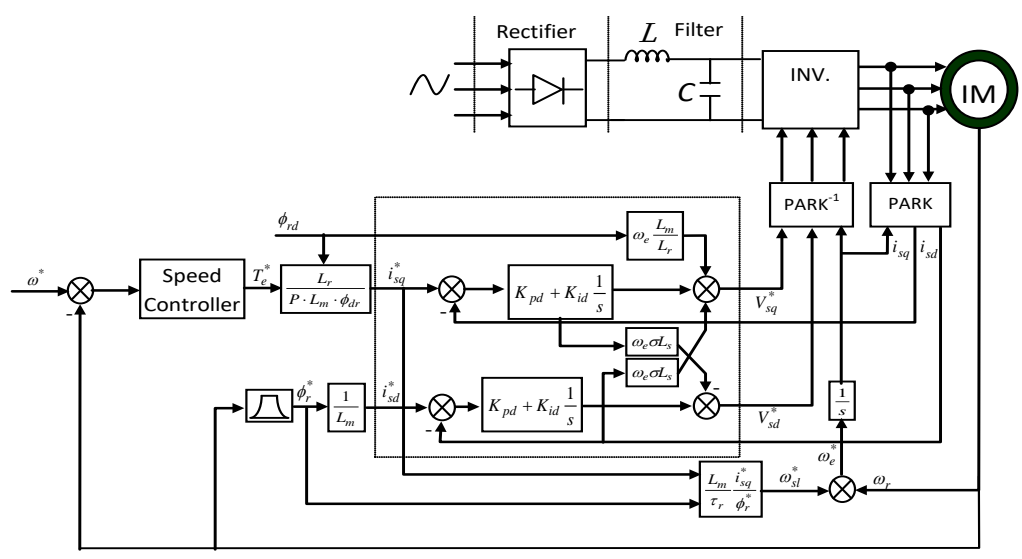

Figure 1. Block diagram of IFOC for the IM 


\section{SPEED CONTROL OF THE IM BY THE ADAPTIVE PI-SLIDING MODE CONTROLLER}

A Sliding Mode Controller is a Variable Structure Controller (VSC). Basically, a VSC includes several different continuous functions that can map plant state to a control surface, and the switching among different functions is determined by plant state that is represented by a switching function [1],[2]. The following is a possible choice of the structure of a sliding mode controller [3],[6]:

$$
u=-k \cdot \operatorname{sgn}(s)+u_{e}
$$

where $u_{e}$ is called equivalent control which is used when the system state is in the sliding mode [5],[15]. $k$ is a constant and it is the maximal value of the controller output. $s$ is called switching function because the control action switches its sign on the two sides of the switching surface $s=0$ is defined as [5],[16]:

$$
s=\dot{e}+\lambda \cdot e
$$

where: $e$ is the error between the speed reference and real speed of the $\operatorname{IM}\left(e=\omega_{r}^{*}-\omega_{r}\right)$.

$\lambda$ is a constant

$\operatorname{sgn}(s)$ is a sign function, which is defined as:

$$
\operatorname{sgn}(s)=\left\{\begin{array}{cc}
-1 & s \leq 0 \\
1 & s>0
\end{array}\right.
$$

The control strategy adopted here will guarantee the system trajectories move toward and stay on the sliding surface $s=0$ from any initial condition if the following condition meets:

$$
s \cdot \dot{s}=\leq-\eta \cdot|s|
$$

where $\eta$ is a positive constant that guarantees the system trajectories hit the sliding surface in finite time [17]. Using a sign function often causes chattering in practice. One solution is to introduce a boundary layer around the switch surface [6],[17]:

$$
u=u_{s}+u_{e}
$$

Where

$$
u_{s}=-k \cdot \operatorname{sat}(s / \Psi)
$$

$\psi$ is the constant factor defines the thickness of the boundary layer, sat(s/ $\psi$ ) is a saturation function that is defined as:

$$
\operatorname{sat}(s / \psi)=\left\{\begin{array}{l|l}
\operatorname{sgn}(s / \psi) & \left|\frac{s}{\psi}\right| \geq 1 \\
s / \psi & \left|\frac{s}{\psi}\right|<1
\end{array}\right.
$$

The function between $u_{s} / k$ and $s / \psi$ is shown in the Figure 2. This controller is actually a continuous approximation of the ideal relay control [5],[17],[18]. The consequence of this control scheme is that invariance of sliding mode control is lost. The system robustness is a function of the width of the boundary layer. To simplify the equivalent control and ease the design task for practicing engineers, Nandam and Sen [6] have proposed an equivalent control action based on the proportional plus derivative control law. A potential advantage of this strategy, which the authors did not address, is its ability of using the undistorted nonlinear model of the physical system in a simulation based design process. Y. Li and al [19] extends this control strategy by incorporating an integration term and to form a generic controller structure. In this study, 
the proportional and integral terms are only used to form equivalent part of the control law, so the proposed generic controller structure is:

$$
u_{e}=u_{s}-\varphi_{P} \cdot e-\varphi_{I} \cdot \int e \cdot d t
$$

With generalized hard-switching parameters are:

$$
\begin{gathered}
\varphi_{p}= \begin{cases}\varphi_{P a} & e \cdot s>\psi \\
\varphi_{P b} & -\psi \leq e \cdot s \leq \psi \\
\varphi_{P c} & e \cdot s<-\psi\end{cases} \\
\varphi_{I}= \begin{cases}\varphi_{I a} & s>\psi \\
\varphi_{I b} & -\psi \leq s \leq \psi \\
\varphi_{I c} & s<-\psi\end{cases}
\end{gathered}
$$

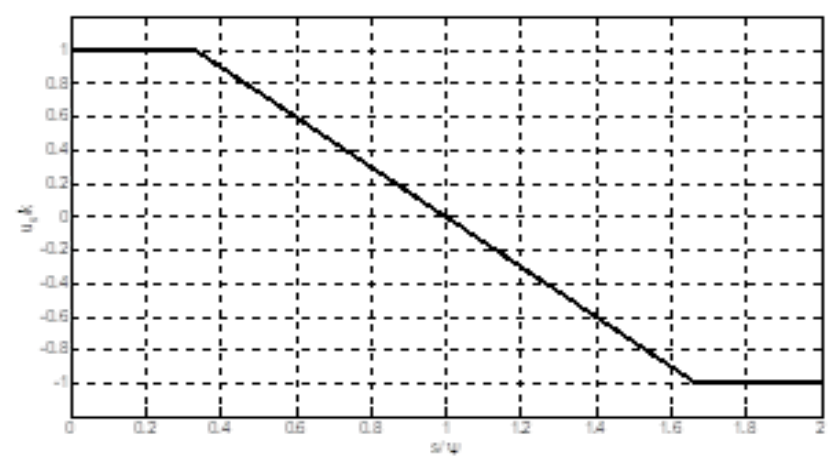

Figure 2. The function between $\frac{u_{s}}{k}$ and $\frac{s}{\psi}$

Figure 3 shows the implemented diagram of the adaptive PI-Sliding mode controller for induction motor speed control.

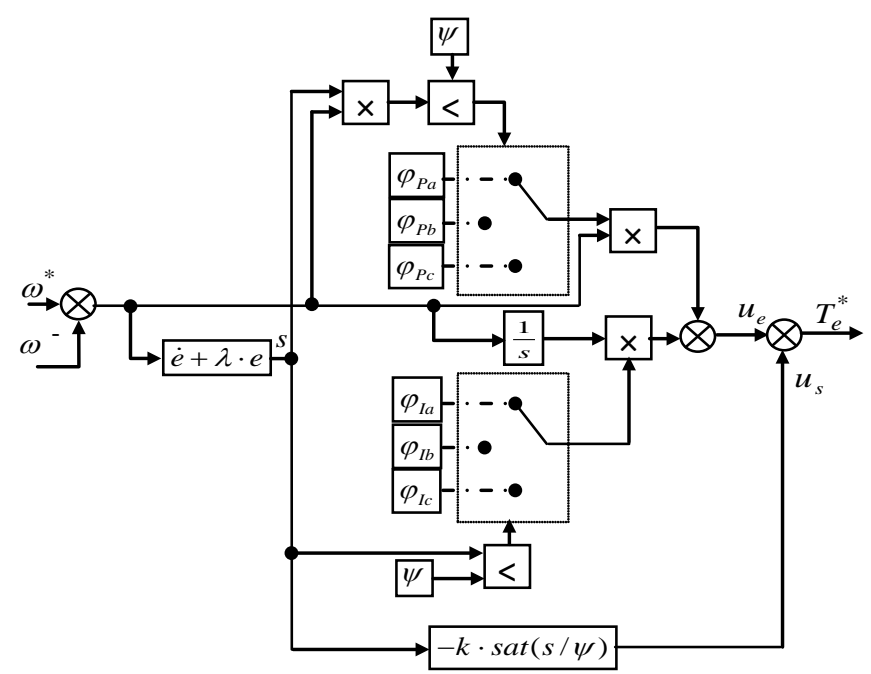

Figure 3. Adaptive PI-Sliding mode controller for induction motor speed control 


\section{SPEED CONTROL OF THE IM BY THE FUZZY ADAPTIVE PI-SLIDING MODE CONTROLLER}

In this section, a fuzzy sliding surface is introduced to develop a sliding mode controller, which the expression $u_{s}=-k \cdot \operatorname{sat}(s / \psi)$ is replaced by an inference fuzzy system for eliminate the chattering phenomenon. The if-then rules of fuzzy sliding mode controller can be described as [6],[20]:

$\mathrm{R} 1:$ if $\mathrm{s}$ is $\mathrm{BN}$ then us is BIGGER

$\mathrm{R} 2$ : if $\mathrm{s}$ is $\mathrm{MN}$ then us is BIG

$\mathrm{R} 3$ : if $\mathrm{s}$ is $\mathrm{JZ}$ then us is MEDUIM

$\mathrm{R} 4$ : if $\mathrm{s}$ is MP then us is SMALL

$\mathrm{R} 5$ : if $\mathrm{s}$ is $\mathrm{BP}$ then us is SMALLER

Where BN, MN, JZ, MP and BP are linguistic terms of antecedent fuzzy set, they mean Big Negative, Medium Negative, Just Zero, Medium Positive, and Big Positive, respectively; see Figure 4 and Figure 5. Figure 6 is the result of defuzzified output us for a fuzzy input s. The block diagram of the fuzzy adaptive sliding mode controller for induction motor speed control is shown in Figure 7.

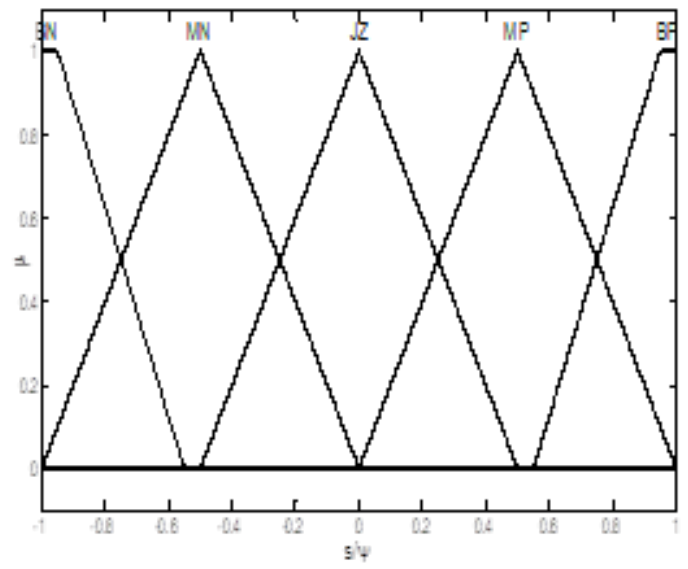

Figure 4. The input membership function of the AFSMC

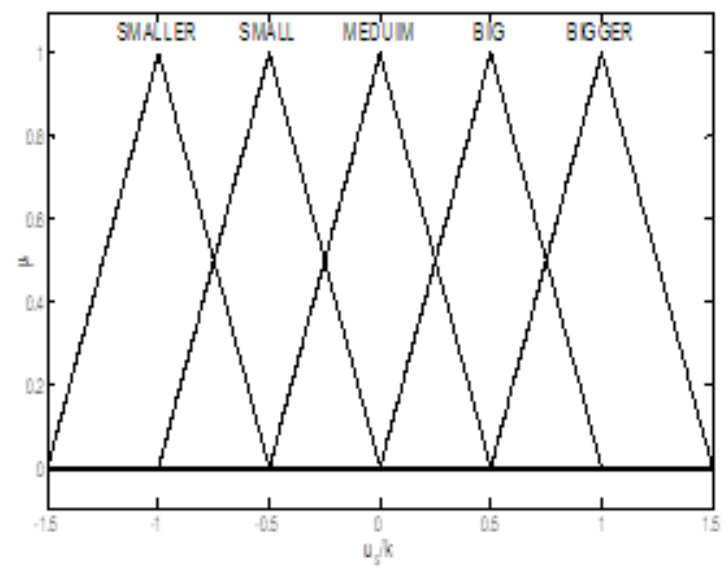

Figure 5. The output membership function of the AFSMC

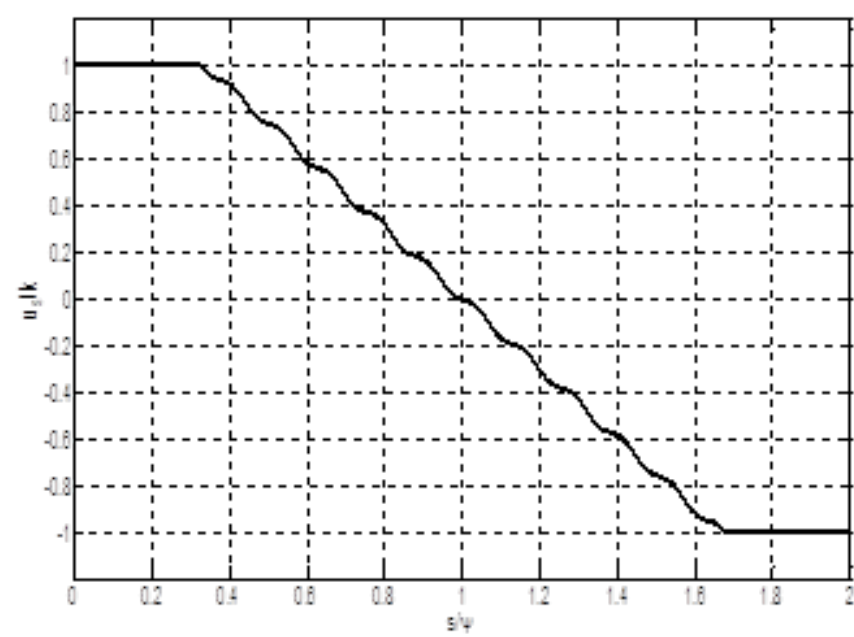

Figure 6. The function between $\frac{u_{s}}{k}$ and $\frac{s}{\psi}$ 


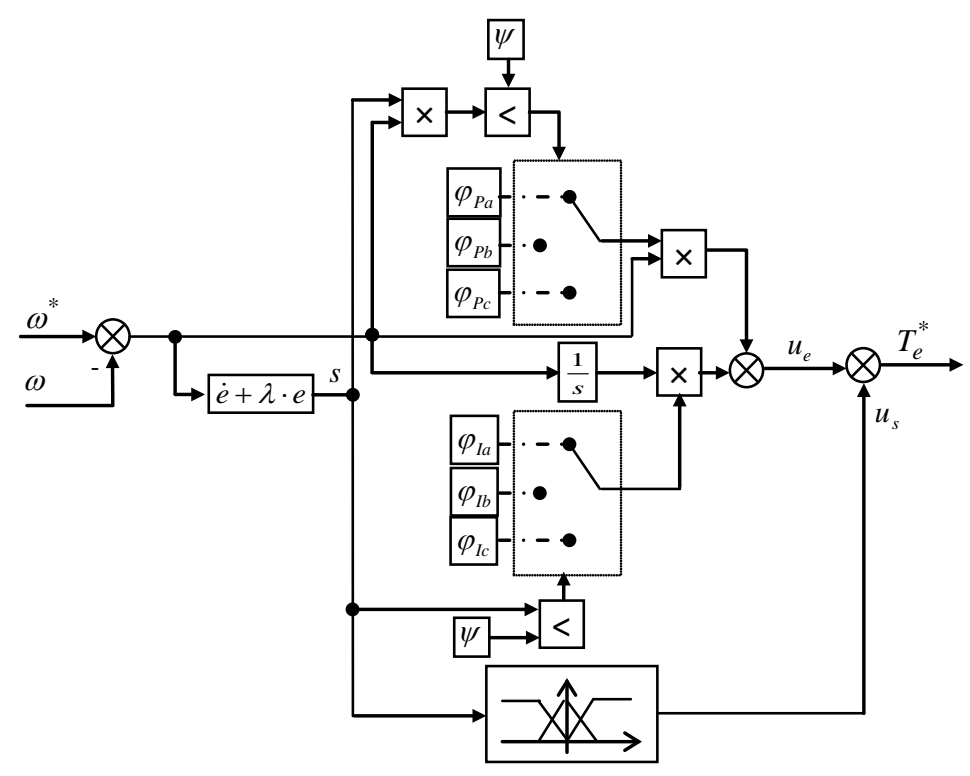

Figure 7. Fuzzy Adaptive PI-Sliding mode controller for induction motor speed control

\section{EXPERIMENTAL RESULTS}

The Figure 8 shows the photo of the experimental banc test which consist of the following elements:

a) Three-phase cage induction motor with the following characteristics: $\Delta$ connected, four poles, $1.5 \mathrm{~kW}$, $1426 \mathrm{~min}-1,230 / 400 \mathrm{~V}, 50 \mathrm{~Hz}$ with the 1024 points integrated incremental coder.

b) Three-phase rectifier,

c) Electrical insulation and adaptation card and current sensor LEM LA25-NP for measuring stator currents (realized in the laboratory),

d) Brushless rotary torque sensor,

e) Powder brake,

f) Measuring device for mechanical quantities,

g) Measuring device for electrical quantities,

h) Load mechanical torque simulator,

i) Three-phase power supply,

j) Relay card for automatic brake control with dSPACE,

k) The dSPACE DS1104 with ControlDesk GUI software for release 6.2.

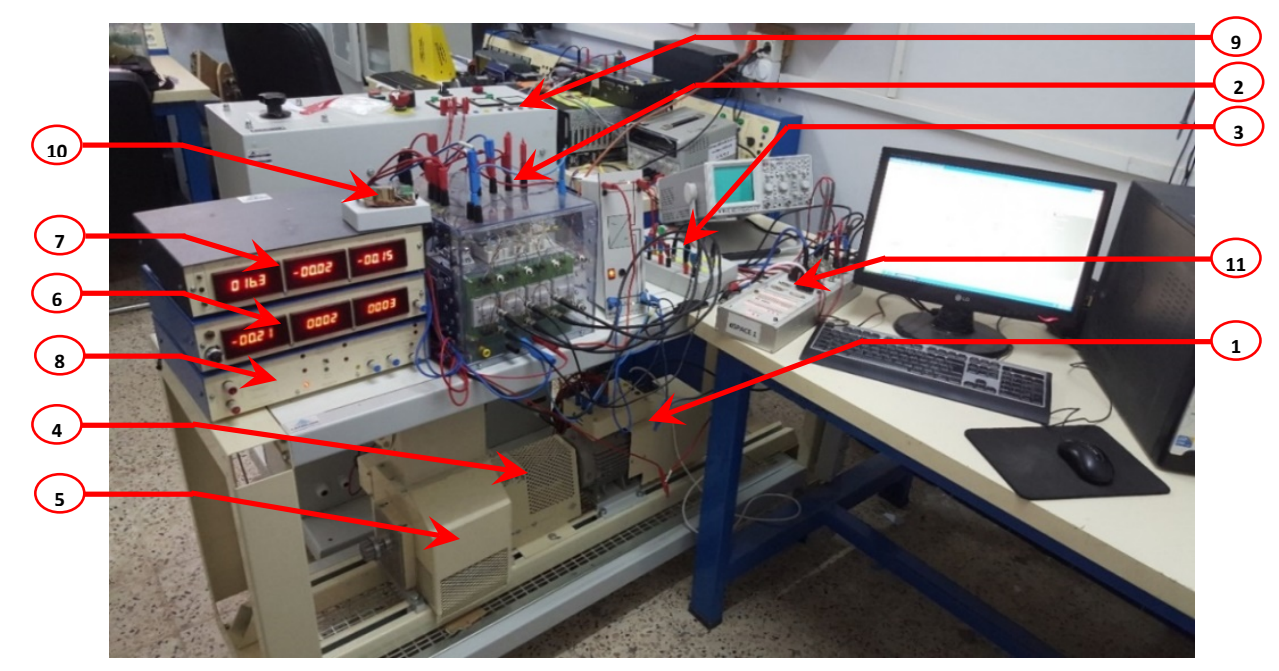

Figure 8. Photo of the experimental banc test 


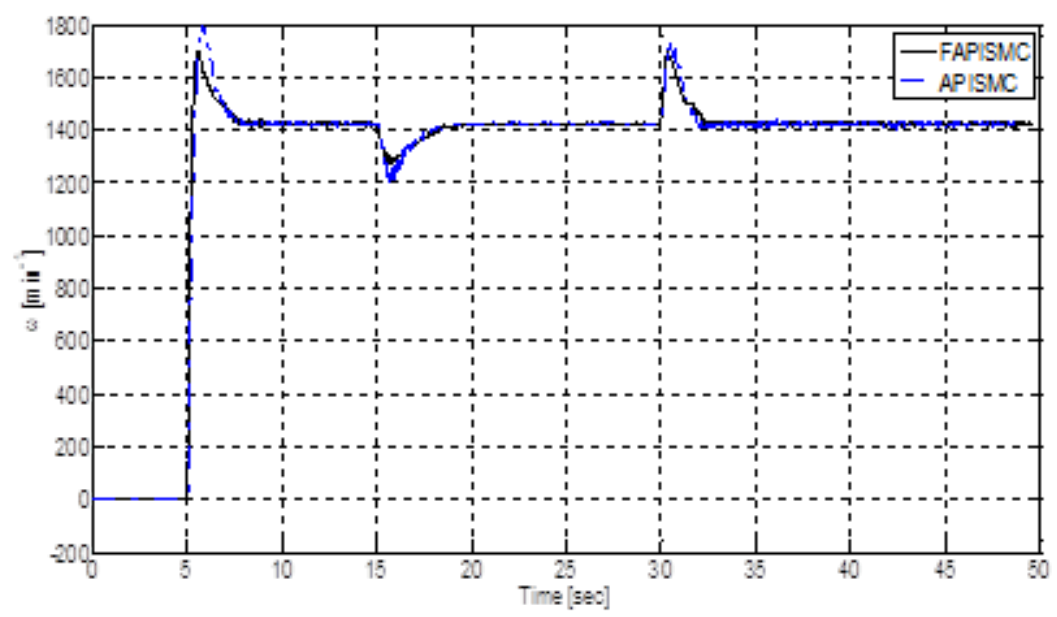

(a) Rotor speed $\left[\mathrm{min}^{-1}\right]$

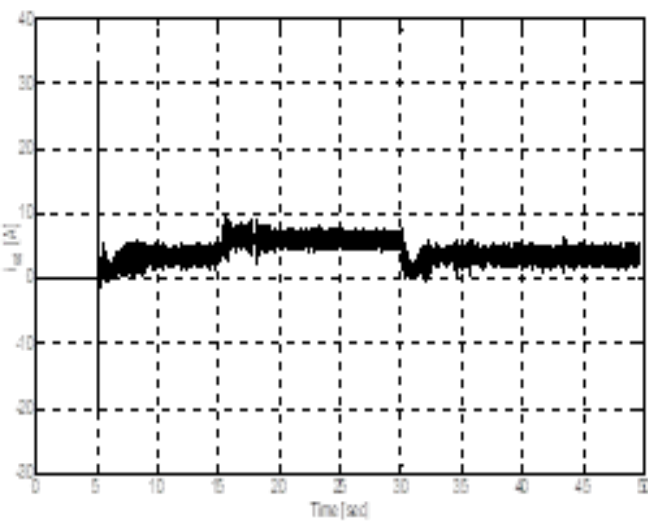

(b) Current $i_{\text {sd }}[\mathrm{A}]$

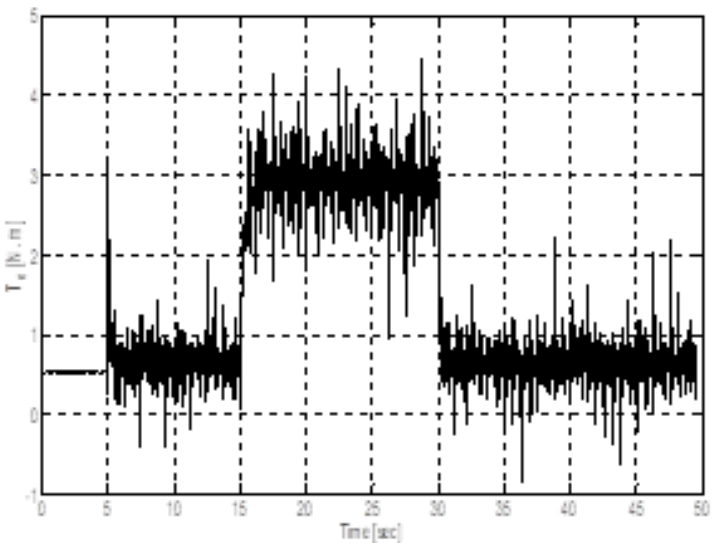

(d) Mechanic torque [N.m]

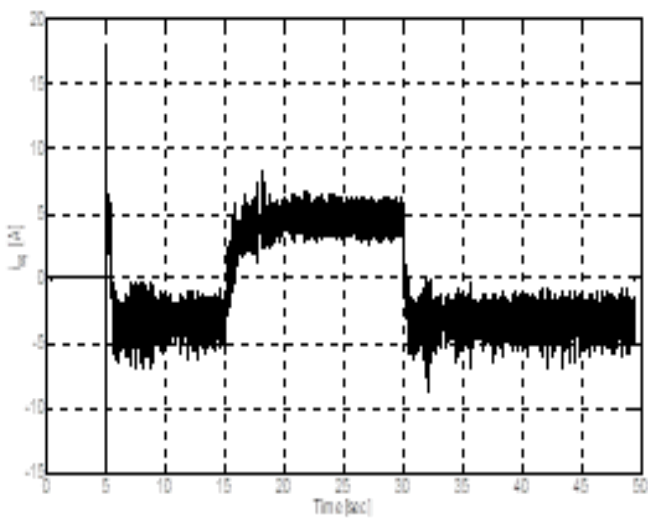

(c) Current $i_{s q}[\mathrm{~A}]$

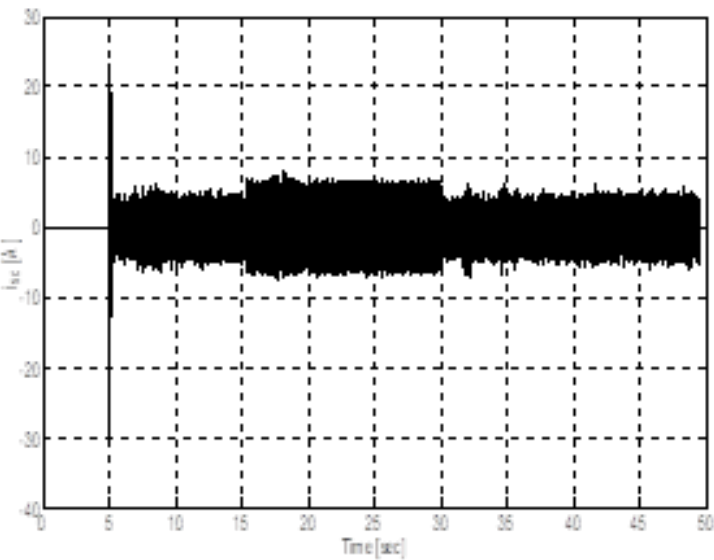

(e) Current isa [A]

Figure 9. Experimental results of the control of the IM by the fuzzy adaptive PI-sliding mode controller under load variation 


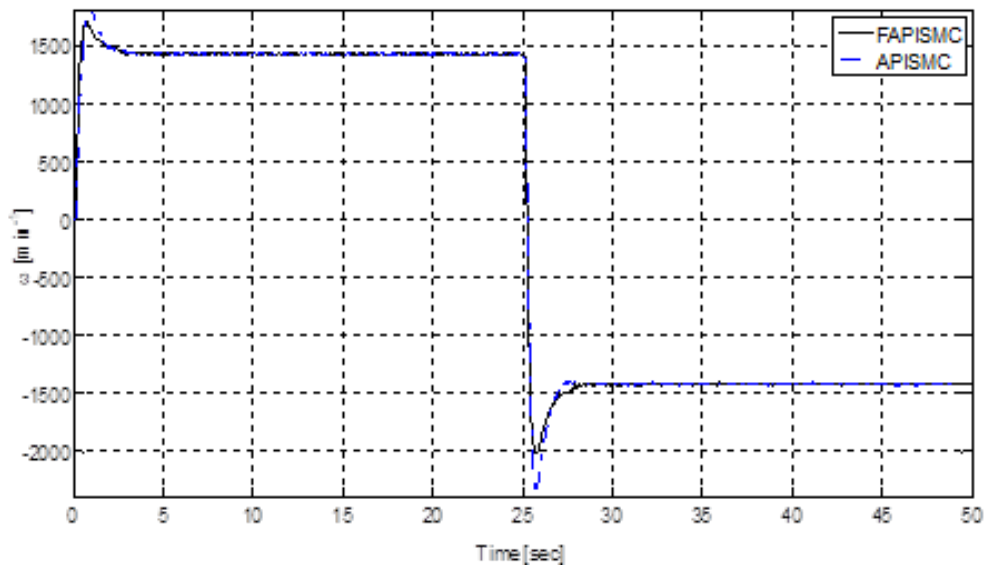

(a) Rotor speed $\left[\mathrm{min}^{-1}\right]$

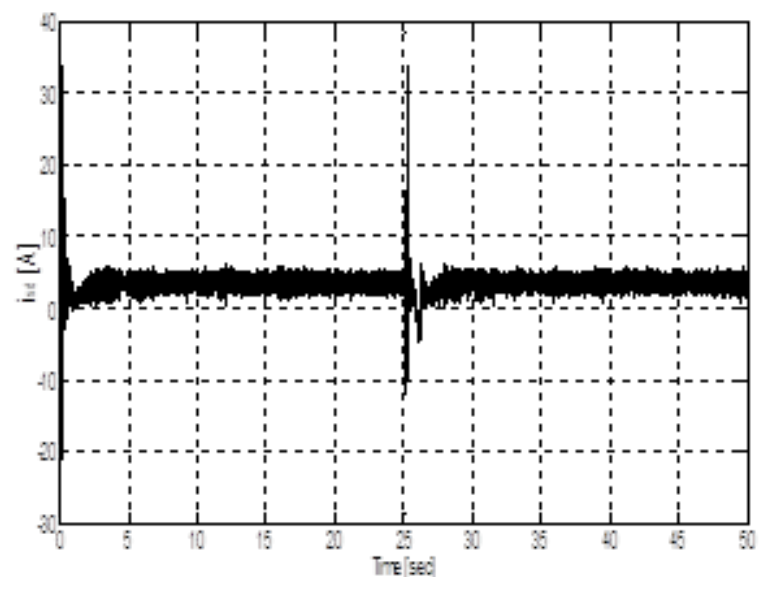

(b) Current isd [A]

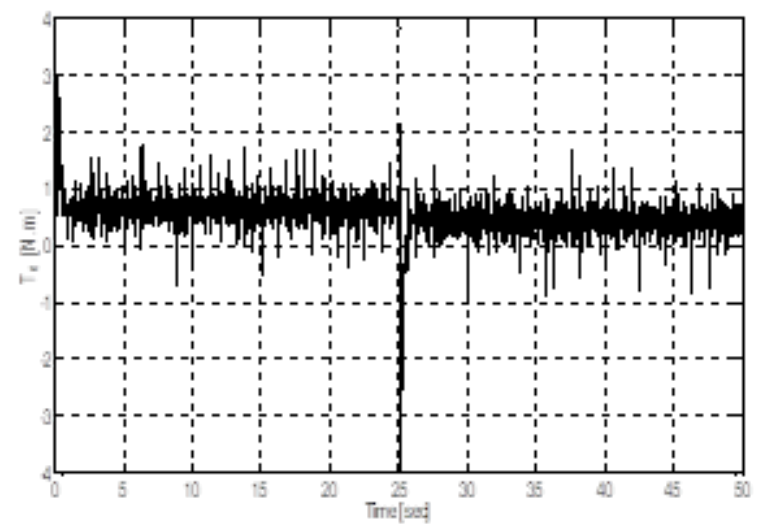

(d) Mechanic torque [N.m]

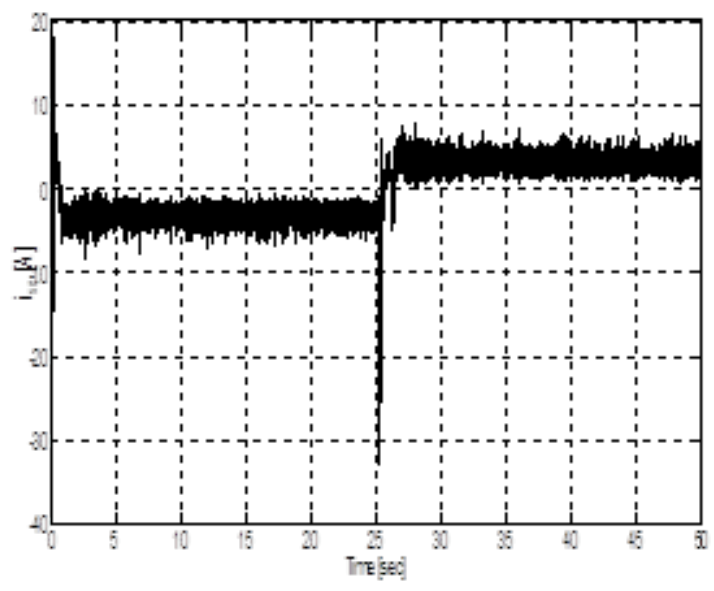

(c) Current isq [A]

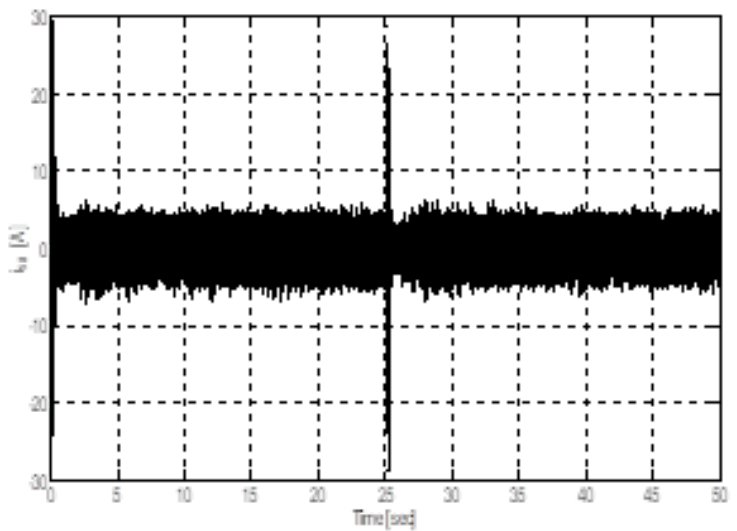

(e) Current isa [A]

Figure 10. Experimental results of the control of the IM by the FAPISMC under reference variation

\section{CONCLUSION}

In this paper a new adaptive fuzzy PI-sliding mode controller is proposed for induction motor speed control, which combines the fuzzy logic with sliding mode control. In this proposed controller, the fuzzy sliding surface is introduced to develop a sliding mode controller, which the expression $u_{s}=-k \cdot \operatorname{sat}(s / \psi)$ is replaced by an inference fuzzy system for eliminate the chattering phenomenon. The proposed scheme has not only attenuate the chattering extent of the adaptive fuzzy PI-sliding mode controller but has presented 
satisfactory performances (minimal overshoot, minimal rise time, best disturbance rejection) for different operating regimes of the IM. Experimental results show that the performance and disturbance rejection with the adaptive fuzzy PI-sliding mode controller is significantly improved as compared to a system with adaptive PI-sliding mode controller.

\begin{tabular}{cccccc}
\multicolumn{5}{c}{ APPENDIX. INDUCTION MOTOR PARAMETERS } \\
\hline$P_{n}[\mathrm{~kW}]$ & 1.5 & $R_{s}[\Omega]$ & 1.5 & $J\left[\mathrm{~kg} / \mathrm{m}^{2}\right]$ & 1.5 \\
$V_{n}[\mathrm{~V}]$ & 230 & $R_{r}[\Omega]$ & 230 & $f_{c}[\mathrm{~N} \cdot \mathrm{m} \cdot \mathrm{s} / \mathrm{rad}]$ & 230 \\
$\cos \varphi$ & 0.82 & $L_{s}[\mathrm{H}]$ & 0.82 & $P$ & 0.82 \\
$\omega_{n}\left[\mathrm{~min}^{-1}\right]$ & 1426 & $L_{r}[\mathrm{H}]$ & 1426 & $\phi_{r}[\mathrm{~Wb}]$ & 1426 \\
$f[\mathrm{~Hz}]$ & 50 & $L_{m}[\mathrm{H}]$ & 50 & $\rho$ & 50 \\
\hline
\end{tabular}

\section{REFERENCES}

[1] V. I. Utkin, "Variable Structure systems with Sliding Modes,” IEEE Transaction on Automatic Control, vol/issue: 22(2), pp. 12-222, 1977.

[2] K. D. Young, et al., "A Control Engineer's Guide to Sliding Mode Control,” IEEE Transactions on Control Systems Technology, vol/issue: 7(3), pp. 328-342, 1999.

[3] F. Plestan, et al., "New methodologies for adaptive sliding mode control," International Journal of Control, vol/issue: 83(9), pp. 1907-1919, 2010.

[4] Y. J. Huang, et al., “Adaptive Sliding-Mode Control for NonlinearSystems With Uncertain Parameters,” IEEE Transactions on Systems, Man, and Cybernetics, Part B (Cybernetics), vol/issue: 38(2), 2008.

[5] R. J. Wai, “Adaptive sliding-mode control for induction servomotor drives,” IEE Proc. Elecrr. Power Appl., vol. 147, pp. 553-562, 2000.

[6] M. Derri, et al., "Fuzzy Sliding Mode Control for Photovoltaic System," International Journal of Power Electronics and Drive System (IJPEDS), vol/issue: 7(3), pp. 964-973, 2016.

[7] Nandam P. K. and P. C. Sen, "Control laws for sliding mode speed control of variable speed drives," Int. J. Control, vol/issue: 56(5), pp. 1167-1186, 1992.

[8] A. Oveisi and T. Nestorović, "Robust observer-based adaptive fuzzy sliding mode controller," Mechanical Systems and Signal Processing, vol. 76, pp. 58-71, 2016.

[9] N. Yagiz, et al., "Fuzzy Sliding-Mode Control of Active Suspensions," IEEE Transactions on Industrial Electronics, vol/issue: 55(11), pp. 3883-3890, 2008.

[10] C. M. Lin and C. F. Hsu, "Adaptive fuzzy sliding-mode control for induction servomotor systems," IEEE Transactions on Energy Conversion, vol/issue: 19(2), pp. 362-368, 2004.

[11] S. Tokat, et al., "A new approaches for online tuning of the linear sliding surface slope in sliding mode controllers," Turk J. Engin., vol/issue: 11(1), 2003.

[12] J. C. Le and Y. H. Kuo, "Decoupled fuzzy sliding-mode control," IEEE Trans. on Fuzzy Systems, vol/issue: 6(3), 1998.

[13] Bose B. K., “Modern Power Electronics and AC Drives,” Prentice Hall, 2002.

[14] R. Arulmozhiyal and K. Baskaran, "Implementation of a Fuzzy PI Controller for Speed Control of Induction Motors Using FPGA,” Journal of Power Electronics, vol. 10, pp. 65-71, 2010.

[15] A. Gouichiche, et al., "Sensorless Sliding Mode Vector Controlof Induction Motor Drives," International Journal of Electrical Engeninring (IJECE), vol/issue: 2(3), pp. 2088-8708, 2016.

[16] V. I. Utkin and A. S. Poznyak, "Adaptive sliding mode control with application to super-twist algorithm: Equivalent control method,” Automatica, vol/issue: 49(1), pp. 39-47, 2013.

[17] Y. X. Su, et al., “Design of an Enhanced Nonlinear PID Controller,” Mechatronics, vol. 15, pp. 1005-1024, 2005.

[18] S. G. Tzafestas and G. G. Rigatos, "Design and stability analysis of a new Sliding mode Fuzzy logic Controller of reduced Complexity,” Machine Intelligence \& Robotic Cont., vol/issue: 1(1), 1999.

[19] N. Bouarroudj, et al., "Sliding-Mode Controller Based on Fractional Order Calculus for a Class of Nonlinear Systems,” International Journal of Electrical Engeninring (IJECE), vol/issue: 6(5), pp. 2088-8708, 2016.

[20] S. Wang, et al., “Adaptive Fuzzy Sliding Mode Control of Uncertain Nonlinear SISO Systems,” Procedia Engineering, vol/ 24, pp. 33-37, 2011. 


\section{BIOGRAPHIES OF AUTHORS}
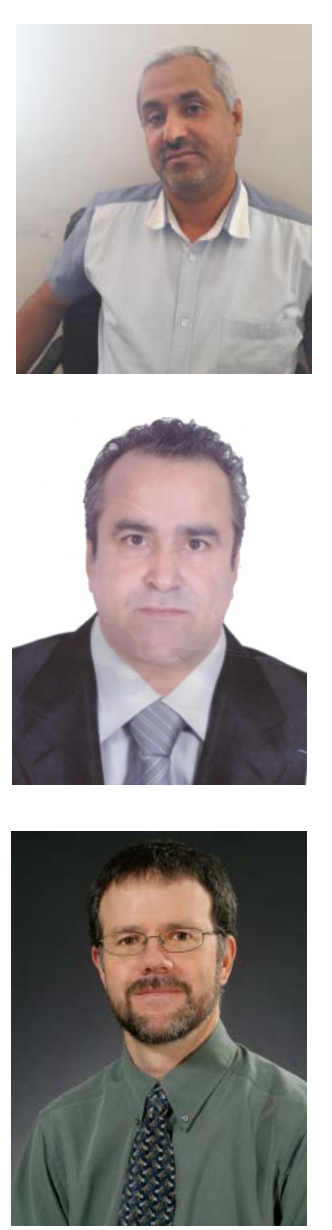

Mohamed HABBAB was born in 1969 at Relizane-Algeria, received the state engineer degree in electronic engineering in 1994 from the University of Sciences and Technology of Oran (USTO), Algeria the M.Sc. degree from the University of Bechar. He’s currently preparing his Ph.d. degree in electronic engineering.

Abdeldjebar HAZZAB received his State Engineer, M.S., and Ph.D degrees in Electrical Engineering from the Electrical Engineering Institute of The University of Sciences and Technology of Oran (USTO), Algeria in 1995, 1999, and 2006, respectively. He is currently a Professor of Electrical Engineering at the University of Bechar (Algeria), where he has been the Director of the Research Laboratory of Command, Analyses, and Optimization of ElectroEnergetic Systems since 2009 at 2014. His research interests include power quality, modeling, modern controller and observer design for nonlinear systems, control of power electronics and multidrive systems, control of power electronics, multidrive systems and electrical vehicle, and adaptive control and nonlinear systems diagnostic, adaptive control, neural networks and fuzzy logic systems.

Pierre SICARD received the bachelor degree in technology of electricity from the Ecole de Technologie Supérieure, Montréal QC, Canada, in 1985, the M. Sc. degree in industrial electronics from the University of Québec in Trois-Rivières, Trois-Rivières, QC, Canada, in 1990, and the Ph. D. degree in electrical engineering from Rensselaer Polytechnic Institute, Troy, New York, USA, in 1993. In 1992, he joined the University of Québec in Trois-Rivières as professor in electrical and computer engineering, where he has been director of the Research Group in Industrial Electronics since 2004. His research interests include power quality, modeling, controller and observer design for nonlinear systems, control of power electronics and multidrive systems, passivity-based control, adaptive control, and neural networks. 